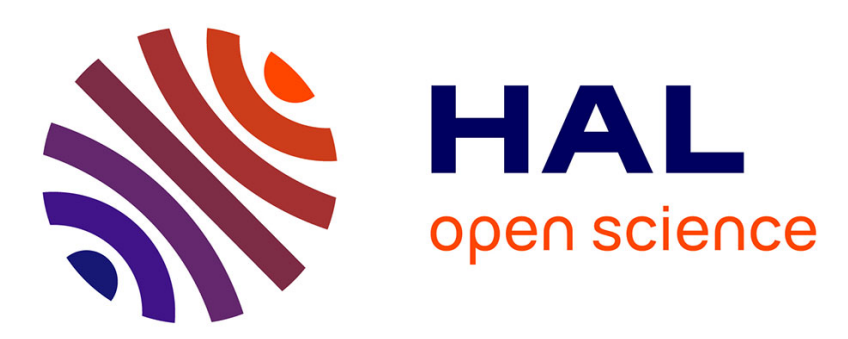

\title{
DIRECT OBSERVATION OF ORBITAL DISSIPATION AND SUPERFLOW COLLAPSE IN 3He-A
}

\author{
M. Bagley, P. Main, J. Hook, D. Sandiford, H. Hall
}

\section{To cite this version:}

M. Bagley, P. Main, J. Hook, D. Sandiford, H. Hall. DIRECT OBSERVATION OF ORBITAL DISSIPATION AND SUPERFLOW COLLAPSE IN 3He-A. Journal de Physique Colloques, 1978, 39 (C6), pp.C6-13-C6-14. 10.1051/jphyscol:1978606 . jpa-00217498

\section{HAL Id: jpa-00217498 https://hal.science/jpa-00217498}

Submitted on 1 Jan 1978

HAL is a multi-disciplinary open access archive for the deposit and dissemination of scientific research documents, whether they are published or not. The documents may come from teaching and research institutions in France or abroad, or from public or private research centers.
L'archive ouverte pluridisciplinaire HAL, est destinée au dépôt et à la diffusion de documents scientifiques de niveau recherche, publiés ou non, émanant des établissements d'enseignement et de recherche français ou étrangers, des laboratoires publics ou privés. 


\title{
DIRECT OBSERVATION OF ORBITAL DISSIPATION AND SUPERFLOW COLLAPSE IN ${ }^{3} \mathrm{He}-\mathrm{A}$
}

\author{
M. Bagley, P.C. Main, J.R. Hook, D.J. Sandiford and H.E. Hall \\ Schuster Laboratory, University of Manchester, Manchester M13 9PL, EngLand.
}

Résumë.- Des expériences de pendule de torsion dans lesquelles le temps de relaxation orbitale est comparable à la période d'oscillation montrent une atténuation fortement dependante de 1'amplitude dans ${ }^{3} \mathrm{He}-\mathrm{A}$ qui est absente dans ${ }^{3} \mathrm{He}-\mathrm{B}$. A forte amplitude, la densité superfluide apparente tend vers zero, suggérant l'effondrement du courant superfluide comme l'ont décrit Bhattacharyya, Ho et Mermin.

Abstract.- Torsion pendulum experiments in which the orbital relaxation time is comparable with the oscillation period show strong amplitude dependent damping in ${ }^{3} \mathrm{He}-\mathrm{A}$ that is absent in ${ }^{3} \mathrm{He}-\mathrm{B}$. At large amplitudes the apparent superfluid density decreases towards zero, suggesting collapse of superflow as described by Bhattacharyya, Ho and Mermin.

In our previous torsion pendulum experiments $/ 1,2 /$ on superfluid ${ }^{3}$ He the width $d$ of the flow chanel was such that the relaxation time of the orbital texture $\tau=\left(\mu / \rho_{s}\right)(2 \mathrm{md} / K)^{2}$ was very much longer than the period of oscillation. In these circumstances we observed an essentially static texture controlled by the mean square relative velocity, $\left(v_{s}-v_{n}\right)^{2}$.

With the object of observing dynamic textures and the concomitant dissipation by orbital viscosity, we have reduced d so that the orbital relaxation time is of the same order as the period of oscillation. The construction of the torsion pendulum is essentially as described previously, but the CMN pill is now surrounded by a stack of 25 toroidal flow channels, each of which is $49 \mu \mathrm{m}$ in height and $0.75 \mathrm{~mm}$ in radial extent. The channels were formed by casting stycast 1266 around aluminium foil and etching away the aluminium after machining was completed.

As before, the oscillation amplitude was controlled by a feedback loop, and the drive level was used as a measure of damping. To facilitate the measurement of absolute amplitudes a capacitance bridge (GR 1621) operating at $10 \mathrm{kHz}$ was used to detect the oscillations, and the suitably phaseshifted output at the pendulum frequency (about 60 $\mathrm{Hz}$ ) was used to trigger the drive voltage. In this self-oscillating mode the oscillation frequency could be read continuously on a frequency counter. Our basic experimental data are thus additional resonance width and frequency shift relative to the normal state; both are of the order of $\mathrm{mHz}$. All the measurements were carried out at the pressure of the melting curve minimum ( 29.7 bar) to avoid pressure fluctuations.

Figure 1 shows two recorder traces of drive level as a function of time during the final stages of demagnetisation and the subsequent warmup. The only difference is that in figure 1 (a) the liquid remained in supercooled $A$-phase throughout, whereas in figure 1 (b) it entered the B-phase. It is clear that at this amplitude (though not at the lowest amplitudes) there is a substancial excess damping in the A-phase but not the B-phase; this alone is strongly suggestive of dissipation by orbital viscosity. The sma1l hydrodynamic damping in the Bphase is attributable to normal shear viscosity. Another feature worthy of note in figure $1(b)$ is that when the liquid returns to the A-phase the dissipation builds up to its full value only rather slowly and in a somewhat erratic manner.

Both damping and frequency shift are roughly proportional to $\left(1-T / T_{c}\right)$. We therefore show in figure 2, as a function of velocity amplitude at $\left(1-T / T_{c}\right)=0.1$, the values of these quantities, normalised to the low amplitude frequency shift. Two features are noteworthy :

(1) the damping maximum, suggesting that we pass through the condition $\omega \tau \sim 1$ as the amplitude increases ;

(2) the great reduction in frequency shift at large amplitudes (which was not observed in the B-phase), implying that the whole liquid is tending to follow the motion of the pendulum.

The second observation, taken together with the slow and erratic return of dissipation after 
a $B \rightarrow$ A transition, strongly suggests that we are observing the collapsed superflow described by Bhattacharyya, Ho and Mermin /3/ ; the delayed return of damping would be associated with the difficulty of surmounting the free energy barrier to formation of the collapsed state.

(a)

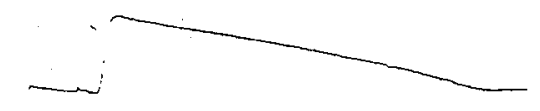

(b)

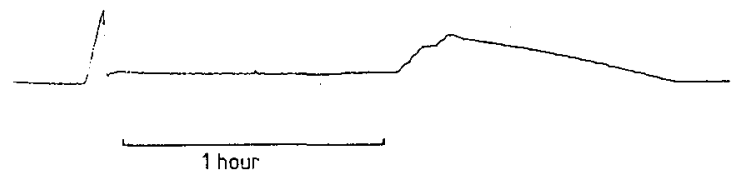

Fig. 1 : Recorder traces of damping as a function of time at an amplitude of $3.0 \mathrm{~mm} / \mathrm{s}$ during the final stages of demagnetisation and the subsequent warmup. In (a) the liquid remained in supercooled A-phase, whereas in (b) it entered the B-phase.

We therefore compare our results with numerical solutions of the equation of motion proposed by Hal1/4/

$\left(\frac{\alpha h}{2 m}\right)^{2} \nabla^{2}\left(\bar{v}_{v s}-v_{v n}^{v_{n}}\right)=\left(\bar{v}_{v s}-v_{v}\right)^{3}+\frac{\beta \mu}{\rho_{s} \perp} \frac{\partial \bar{v}}{\partial t}$,

with the boundary conditions $\bar{v}_{s}=0$ at the walls and $v_{n}=v_{0}$ sin wt everywhere. From the solution we compute the rate of change of momentum and hence the torque on our torsion pendulum.

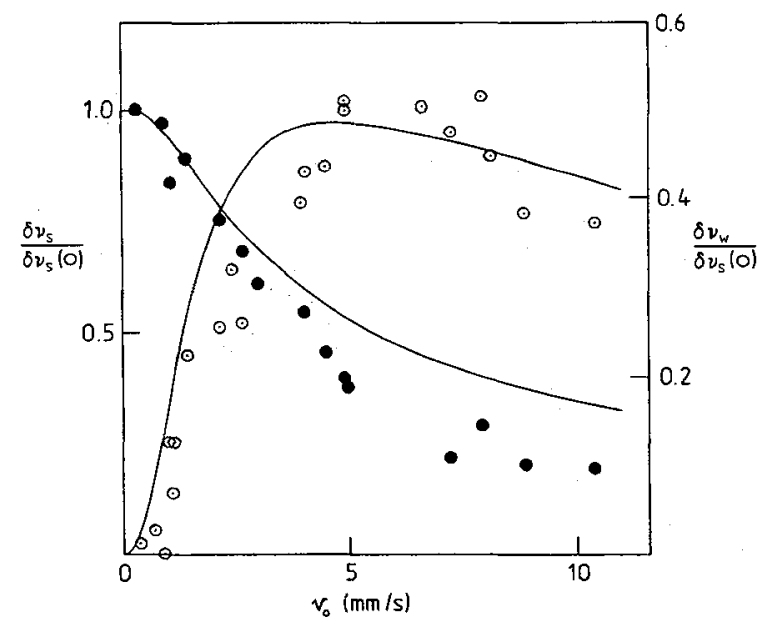

Fig. 2 : Normalised frequency shift $\delta V_{\text {(solid }}$ points) and extra resonance width $\delta v$ (open points) as a function of velocity amplitude $\mathrm{W}$. The curves are computed from eq. 1 with $\alpha^{2}=2.5^{\circ}$ and $\beta=2.0$.
The full curves in figure 2 are calculated for $\alpha^{2}=5.0$ and $\left(\beta \mu / \rho_{\mathrm{s}}\right)=1.2 \times 10^{-4} \mathrm{~cm}^{2} \mathrm{~s}^{-1}$, which with the measured value of $\mu / 5 /$ gives $\beta=4.0$. These parameters give about the best overall fit ; larger values fit the low amplitude damping better, and smaller values fit the high amplitude frequency shift better.

In view of the considerable oversimplification involved in using the single parameter $\bar{y}_{s}$ to describe changes in supercurrent resulting from the effect of textures on $\chi_{s}, \&_{s}$, and curl $\&$, we consider that eq. (1) describes our results as well as can reasonably be expected. Certainly, the agreement over the general form of the results give us considerable confidence that the ideas of superflow collapse and orbital relaxation on which eq. (1) is based are essentially correct.

\section{References}

/1/ Main, P.C., Kiewiet, C.W., Band, W.T., Hook, J.R., Sandiford, D.J., and Hal1, H.E., J. Phys. C 9 (1976) L 397.

/2/ Main, P.C., Band, W.T., Hook, J.R., Hall, H.E. and Sandiford, D.J., Quantum Fluids and Solids, ed. Trickey S.B., Adams E.D., and Duffy J.W. (Plenum 1977) p. 117.

/3/ Bhattacharyya, P., Ho $\mathrm{T}-\mathrm{L}$, and Mermin, N.D., Phys. Rev. Lett. 39 (1977) 1290, 1691.

/4/ Hall, H.E., paper at this conference.

/5/ Paulson, D.N., Krusius, M. and Wheatley, J.C., Phys. Rev. Lett. 36 (1976) 1322. 